\title{
Phase Transition Studies in Polymesomorphic Compounds II. Ultrasonic Velocity Studies in N(p-n-Heptyloxy Benzylidene)p-n-Butyl Aniline
}

\author{
V. G. K. M. Pisipati * and N. V. S. Rao ** \\ Faculty of Physical Sciences, Nagarjuna University, Nagarjuna Nagar, India
}

Z. Naturforsch. 37 a, 1262-1265 (1982); received May 24, 1982

The variation of ultrasonic velocity in N(p-n-heptyloxy benzylidene)p-n-butyl aniline, (HyBBA) with temperature in isotropic, nematic, smectic-A, smectic-C and smectic-G phases is measured. All the phase transitions I-N, N-S $\mathrm{S}_{\mathrm{A}}, \mathrm{S}_{\mathrm{A}}-\mathrm{S}_{\mathrm{C}}$ and $\mathrm{S}_{\mathrm{C}}-\mathrm{S}_{\mathrm{G}}$ are found to be of first order. The adiabatic compressibility $\beta_{\mathrm{ad}}$, molar sound velocity or Rao number $R_{\mathrm{n}}$, and molar compressibility or Wada constant $A_{\mathrm{w}}$ are computed. $R_{\mathrm{n}}$ and $A_{\mathrm{w}}$ of $\mathrm{HyBBA}$ are compared with theoretical values and found to be in good agreement with the theory.

\section{Introduction}

A physical system in which a phase transition can occur is usually characterised by one or more long range order parameters [1]. For example, the nematic liquid crystalline phase possesses long range orientational ordering of the molecules, while the smectic phases possesses three, two or one dimensional periodic ordering of the molecules in addition to the orientational ordering [2]. The state of the system at any fixed temperature can be described by an equilibrium value of the molecular parameter and fluctuations about that value. A phase transition can be accompanied by either a continuous or discontinuous or anomalous change in the equilibrium value of the molecular parameter when the system transforms from one phase to the other [3]. The determination of molecular properties such as ultrasonic velocity and molecular volume in a range of temperatures allows one to infer the nature of the phase transition, whether first or second order, the nature of the molecular packing and of the molecular interactions.

Even though the first ultrasonic experiments on liquid crystals were reported by Gabrielli and Verdini [4] as early as in 1955, the accumulated data on ultrasonic studies to date is meagre and is referred in the review articles by Natale [5]. The ultrasonic experimental studies of phase transitions

* Department of Physics.

** Department of Chemistry.

Reprint requests to Dr. N. V. S. Rao, Department of Chemistry, Faculty of Physical Sciences, Nagarjuna University, Nagarjuna Nagar 522510, Indien. are so far limited to I-N, I-S $, I-C h, N-S_{A}, N-S_{C}$, $\mathrm{S}_{\mathrm{B}}-\mathrm{S}_{\mathrm{A}}$ and $\mathrm{Ch}-\mathrm{S}_{\mathrm{A}}$ transitions [6].

The $\mathrm{N}$-(p-n-alkoxybenzylidene) - $\mathbf{p}^{\prime}$-n-alkylanilines exhibit complex mesomorphism [7-11]. Detailed study of the phase transitions by different techniques such as $\mathrm{X}$-rays $[10,11]$, thermal microscopy $[9,10]$ DSC, DTA etc., are reported by various authors. However ultrasonic velocity and molar volume studies are meagre for these compounds. These compounds are denoteed as $n \mathrm{O} \cdot \mathrm{m}$ compounds, where $n$ and $m$ represent the numbers of carbon atoms in the alkoxy and the alkyl groups, respectively, attached to the benzylidene-aniline skeleton in the para-positions. The higher homologues in this series exhibit only smectic phases followed by either a narrow range of nematic phase or no nematic phase. The higher homologues commonly exhibit smectic-A phases at high temperatures, followed by a narrow range of smectic-C or smectic$\mathrm{B}$ or smectic-F and finally smectic-G phase at lower temperatures. Thus the detection of phase transitions from nematic to smectic-A, smectic-A to smectic-B (or C or F) and smectic-B (or C or F) to smectic$\mathrm{G}$ by different methods can confirm the above transitions conclusively.

In our recent experiments involving density studies [12] on the phase transitions of HyBBA, $\mathrm{N}$-(p-n-heptyloxybenzylidene) -p-n-butylaniline, peculiar results were found. Therefore it seems worth carrying out measurements of the ultrasonic velocity for HyBBA at different temperatures to provide conclusive evidence about the order of the phase transitions.

The present study is carried out on the compound 
HyBBA (70.4). The phase transitions observed by ultrasonic velocity studies are found to be compatible with our thermal microscopy, density results, and literature data. The phase transition temperatures for the compound HyBBA are given below.

$$
\mathrm{C}_{7} \mathrm{H}_{15} \mathrm{O}-\langle\underline{\bar{o}}\rangle-\mathrm{CH}=\mathrm{N}-\langle\underline{\bar{o}}\rangle-\mathrm{C}_{4} \mathrm{H}_{9}
$$

Solid $\stackrel{30,0^{\circ} \mathrm{C}}{\longrightarrow}$ Smectic-G $\stackrel{63^{\circ} \mathrm{C}}{\longrightarrow}$ Smectic-C $\stackrel{64.8^{\circ} \mathrm{C}}{\longrightarrow}$

Smectic-A $\stackrel{74.6^{\circ} \mathrm{C}}{\longrightarrow}$ Nematic $\stackrel{76.6^{\circ} \mathrm{C}}{\longrightarrow}$ Isotropic.

\section{Experimental}

The synthesis of the compound is described elsewhere [12]. The compound exhibits smectic-smectic, smectic-nematic and nematic isotropic transitions at temperatures which are accurate to within $0.1{ }^{\circ} \mathrm{C}$ for both heating and cooling cycles.

The ultrasonic velocity was measured at a frequency of $2 \mathrm{MHz}$ using the ultrasonic interferometer UF 101 N.P.L., India. The cell was essentially the same as the supplied with the interferometer except for a few modifications for making the reflector and transducer more nearly parallel with a minimum spacing of $0.4 \mathrm{~cm}$ and for heating an arrangement. The temperature of the cell was controlled by controlling the voltage across the heating element arranged in a brass block surrounding the cell. The temperature accuracy is $\pm 0.1^{\circ} \mathrm{C}$ and the ultrasonic velocity measurements are accurate to $\pm 0.1 \%$.

\section{Results and Discussion}

The ultrasonic velocity at different temperatures, along with the molar volumes calculated from the density results [12], are presented in Table 1 . The variation of the ultrasonic velocity with temperature is displayed in Figure 1. The ultrasonic velocity in the isotropic phase of $\mathrm{HyBBA}$ increases linearly with decreasing temperature as in normal liquids. An anomalous decrease in the ultrasonic velocity (Fig. 1) is observed in the vicinity of the isotropicnematic phase transition. The ultrasonic velocity first decreases in the isotropic phase near the transition and then increases with decreasing temperature in the nematic phase. The anomalous decrease is $0.7 \%$, which is smaller than that for other systems reported earlier $[5,12-14]$. We believe that the small decrease in the ultrasonic velocity at this transition is due to some smectic type ordering that may exist in the nematic phase thereby causing a small change in
Table 1. Molar volume Mv and ultrasonic velocity $V$ at different temperatures for $\mathrm{HyBBA}$.

\begin{tabular}{|c|c|c|c|c|c|}
\hline $\begin{array}{l}\text { Tem- } \\
\text { pera- } \\
\text { ture } \\
{ }^{\circ} \mathrm{C}\end{array}$ & $\begin{array}{l}\text { Molar } \\
\text { Volume } \\
\mathrm{cm}^{3}\end{array}$ & $\begin{array}{l}\text { Ultra- } \\
\text { sonic } \\
\text { Velocity } \\
\text { metre/sec }\end{array}$ & $\begin{array}{l}\text { Tem- } \\
\text { pera- } \\
\text { ture } \\
{ }^{\circ} \mathrm{C}\end{array}$ & $\begin{array}{l}\text { Molar } \\
\text { Volume } \\
\mathrm{cm}^{3}\end{array}$ & $\begin{array}{l}\text { Ultra- } \\
\text { sonic } \\
\text { Velocity } \\
\text { metre/sec }\end{array}$ \\
\hline 84.0 & 373.39 & 1309.2 & 73.0 & 365.35 & 1326.6 \\
\hline 83.0 & 372.99 & 1312.0 & 72.5 & 365.11 & 1334.4 \\
\hline 82.5 & 372.81 & 1313.5 & 72.0 & 364.88 & 1339.6 \\
\hline 82.0 & 372.62 & 1314.8 & 70.9 & 364.44 & 1344.0 \\
\hline 81.5 & 372.42 & 1316.4 & 70.5 & 364.29 & 1345.2 \\
\hline 80.5 & 372.00 & 1319.0 & 69.0 & 363.69 & 1352.4 \\
\hline 80.0 & 371.80 & 1320.0 & 68.0 & 363.37 & 1355.7 \\
\hline 79.5 & 371.60 & 1321.6 & 67.5 & 363.19 & 1357.0 \\
\hline 78.6 & 371.21 & 1322.8 & 67.0 & 363.00 & 1358.0 \\
\hline 78.0 & 370.98 & 1323.2 & 66.4 & 362.78 & 1360.6 \\
\hline 77.4 & 370.63 & 1320.4 & 66.1 & 362.66 & 1362.1 \\
\hline 77.0 & 370.12 & 1319.6 & 65.8 & 362.55 & 1362.5 \\
\hline 76.7 & 369.75 & 1319.6 & 65.6 & 362.47 & 1362.0 \\
\hline 76.6 & 369.61 & 1318.0 & 65.2 & 362.35 & 1361.0 \\
\hline 76.5 & 369.40 & 1322.8 & 64.9 & 362.26 & 1360.5 \\
\hline 76.2 & 369.07 & 1324.0 & 64.8 & 362.21 & 1360.0 \\
\hline 76.0 & 368.91 & 1318.2 & 64.7 & 362.18 & 1361.3 \\
\hline 75.5 & 368.37 & 1316.8 & 64.5 & 362.10 & 1361.8 \\
\hline 75.0 & 367.71 & 1296.0 & 64.0 & 361.93 & 1362.1 \\
\hline 74.8 & 367.38 & 1292.4 & 63.8 & 361.83 & 1363.6 \\
\hline 74.7 & 367.25 & 1291.2 & 63.6 & 361.74 & 1362.0 \\
\hline 74.6 & 366.95 & 1290.0 & 63.5 & 361.68 & 1361.0 \\
\hline 74.5 & 366.86 & 1291.2 & 63.3 & 361.49 & 1359.0 \\
\hline 74.0 & 366.14 & 1299.0 & 63.2 & 361.40 & 1358.0 \\
\hline 73.9 & 365.96 & 1306.0 & 63.1 & 361.29 & 1357.6 \\
\hline 73.7 & 365.80 & 1313.3 & 63.0 & 360.99 & 1374.4 \\
\hline 73.1 & 365.40 & 1323.6 & 62.8 & 360,57 & 1387.2 \\
\hline
\end{tabular}

the ultrasonic velocity at this transition. If such interference by pretransitional effects is not present there should be a large anomalous change in the ultrasonic velocity at this transition in accordance

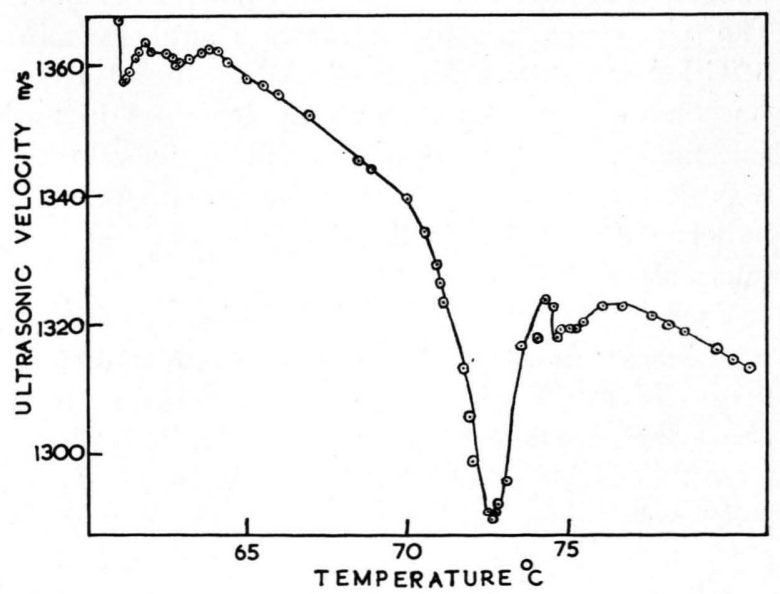

Fig. 1. Temperature variation of ultrasonic velocity in smectic-G, smectic-C, smectic-A and nematic phases of HyBBA. Read 65, 70, and 75 as 67,72 , and 77 respectively. 
with other experimental results, and since the transformation from the isotropic liquid to the nematic phase involves the arrangement of disordered molecules into an ordered arrangement of molecules with long range orientational ordering. It is also observed that the anomalous change in ultrasonic velocity extends over about $1.5^{\circ} \mathrm{C}$ to $3{ }^{\circ} \mathrm{C}$ in other samples. Hence pretransitional effects are present on the nematic side of the isotropic-nematic transition.

The nematic phase exists for only $2{ }^{\circ} \mathrm{C}$ and then a transition from the nematic to the smectic-A phase follows. An anomalous change in ultrasonic velocity is observed at this phase transition. The anomalous decrease amounts to $2.7 \%$ when compared with the normal behaviour of ultrasonic velocity with temperature. The discontinuity in molecular diffusion in the nematic phase and the development of one-dimensional periodic ordering, in addition to the long range orientational ordering of the molecules in the nematic phase, in the smectic-A phase explains the observed velocity dip at the transformation of the nematic to the smectic-A phase. These results support a first order nematicsmectic-A phase transition. Similar ultrasonic studies at nematic-smectic-A phase transitions have confirmed the first order nature of such phase transitions in TBBA (terephthalylidene-bis-4-n-butylaniline) [15] and HBBA (N-(p-n-hexyloxybenzylidene) - $\mathrm{p}^{\prime}$ n-butylaniline) [16]. Theory [17] predicts a first order $\mathrm{N}-\mathrm{S}_{\mathrm{A}}$ transition for values of $\left(T_{\mathrm{NA}} / T_{\mathrm{NI}}\right) \geqq$ 0.88. The value of $\left(T_{\mathrm{NA}} / T_{\mathrm{NI}}\right)$ is 0.99 for this compound. Pretransitional effects are found to occur on both sides of the nematic-smectic-A phase transition. The ultrasonic velocity increases sharply within $3{ }^{\circ} \mathrm{C}$ below the nematic-smectic-A transition, in the smectic-A phase, and then slowly increases in the smectic-A phase. The change in ultrasonic velocity with decreasing temperature in the smectic-A phase indicates a variation in the molecular packing and intermolecular distance.

The smectic-A to smectic-C transition at $64.8^{\circ} \mathrm{C}$ is of interest because the compound exhibits narrow ranges of smectic-C and nematic phase below and above the smectic-A phase, respectively. This phase transition is indicated by a small dip in the ultrasonic velocity at this temperature. The smectic-C phase is the tilted analogue of the smectic-A phase, and both the phases have unstructured layers. The ultrasonic velocity studies support a first order transition. It is also observed through thermal

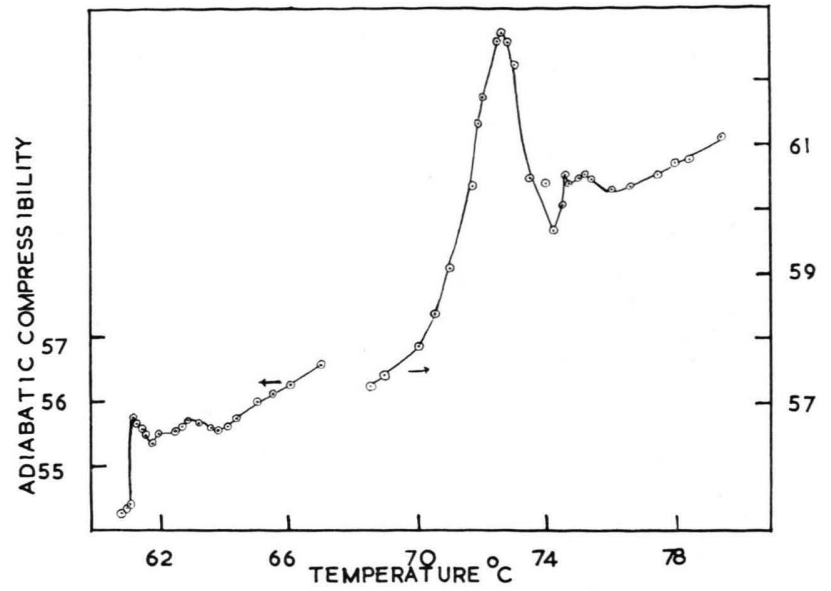

Fig. 2. Variation of adiabatic compressibility $\beta_{\mathrm{ad}}$ (in $\times 10^{-12} \mathrm{~cm}^{2} /$ dyne) with temperature for HyBBA. Read $62,66,70,74$, and 78 as $64,68,72,76$, and 80 respectively.

microscopy that the focal conic texture of the smecticA phase is changed to the broken focal-conic texture characteristic of a smectic-C phase. The density studies [12] do not reveal this transition, but the thermal expansion coefficient does infer it. Hence we believe that this symectic-C to smectic-A transition is a weak first order transition. The transition energy [9], which is very small $(40 \mathrm{cal} / \mathrm{mol})$ at this transition, also supports the above observations.

The smectic-C to smectic-G transition can also be inferred from the ultrasonic studies. However the detection of ultrasonic velocity in the smectic-G phase is difficult experimentally. The ultrasonic velocity sharply increases to a very high value below

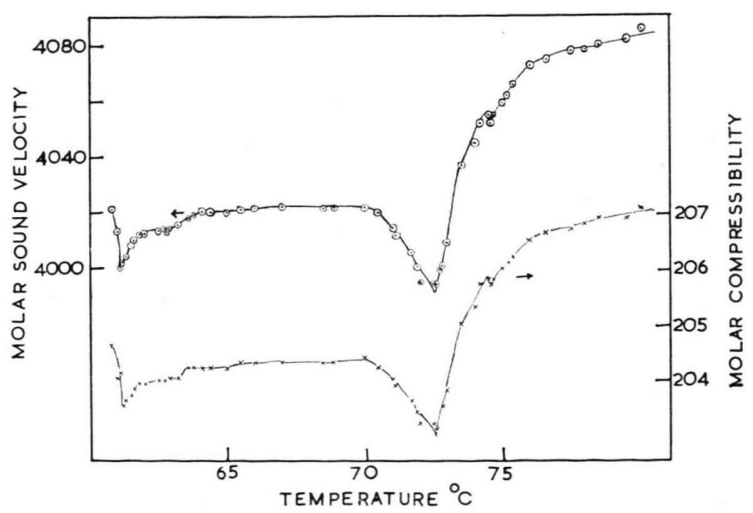

Fig. 3. Variation of molar sound velocity $R_{\mathrm{n}}$ (in $\mathrm{cm}^{3}$ (metre/sec) $)^{1 / 3}$ ) and molar compressibility $A_{\mathrm{W}}$ (in $\mathrm{cm}^{3}$ (dyne $\left./ \mathrm{cm}^{2}\right)^{1 / 7} \cdot 10^{12 / 7}$ ) with temperature for HyBBA. Read 65,70 , and 75 as 67,72 , and 77 respectively. 
the transition temperature. This transition involves a change from one-dimensional to three-dimensional periodicity and is indicated by a sharp increase in ultrasonic velocity below this temperature.

The adiabatic compressibility $\beta_{\mathrm{ad}}$, molar sound velocity or Rao number $R_{\mathrm{n}}$ [18], and molar compressibility or Wada constant $A_{\mathrm{W}}$ [19] are computed using the ultrasonic velocity and molar volume data. The adiabatic compressibility variation with temperature is illustrated in Figure 2. $\beta_{\text {ad }}$ decreases linearly in the isotropic, nematic-smectic-A, smectic$\mathrm{C}$ and smectic- $\mathrm{G}$ phases with decreasing temperature outside the vicinity of the phase transitions. All the phase transitions are indicated by small bumps or peaks with an increase in $\beta_{\mathrm{ad}}$ above the transition and a decrease in $\beta_{\mathrm{ad}}$ below the transition with the decreasing temperature.

The molar sound velocity and molar compressibility are plotted in Figure 3. The transitions are indicated by the minima in the molar sound velocity and molar compressibility. Pretransitional effects are found to occur on both sides of the transition temperatures. However they are found to be unsym-

[1] P. G. de Gennes, The Physics of liquid crystals, Oxford University Press, London 1974, Chapter-2.

[2] A. de Vries, Mol. Cryst. Liq. Cryst. 63, 215 (1981).

[3] P. Sheng and E. B. Priestley, Introduction to liquid crystals, Plenum Press, New York 1975, Chapter-10.

[4] I. Gabrielli and L. Verdini, Nouvo Cim. 2, 426 (1955).

[5] G. G. Natale, J. Acoust. Soc. Amer. 63, 1265 (1978).

[6] G. G. Natale, J. Acoust. Soc. Amer. 65, 1677 (1978).

[7] J. B. Flannery and W. Hass, J. Phys. Chem. 74, 3611 (1970).

[8] P. R. Patel, Indian J. Chemistry 50, 514 (1973).

[9] G. W. Smith and Z. G. Gardlund, J. Chem. Phys. 59, 3214 (1973).

[10] A. J. Leadbetter, M. A. Mazid, B. A. Kelly, J. W. Goodby, and G. W. Gray, Phys. Rev. Lett. 43, 630 (1979); J. W. Goodby, G. W. Gray, A. J. Leadbetter, and M. A. Mazid, in "Liquid Crystals of One- and Two-Dimensional Order", eds. W. Hefrich and G. Heppke, Springer-Verlag, Berlin 1980, p. 3. metric about the transition temperatures and occur markedly on the low temperature side. The petransitional effects can be explained on the basis of Frenkel's heterophase fluctuation theory [20].

The molar sound velocity for HyBBA is computed theoretically from atomic velocity data of Rao [18] and bond velocity data of Lagemann and Corey [21]. The calculated value of $R_{\mathrm{n}}$ from ultrasonic velocity and molar volume results is $4080 \mathrm{~cm}^{3}$ $(\mathrm{m} / \mathrm{sec})^{1 / 3}$ and is found to be lower than the $R_{\mathrm{n}}$ values estimated from atomic data (4163) and bond data (4243). The computed $A_{\mathrm{W}}$ from the experimental ultrasonic velocity and molar volume data is $206.2 \mathrm{~cm}^{3}\left(\text { dyne } / \mathrm{cm}^{2}\right)^{1 / 7} \cdot 10^{12 / 7}$ and is found to be in reasonable agreemeent with the theoretical value of 205.4 from Wada's table [19].

\section{Acknowledgements}

The authors are grateful to Prof. D. Premswarup and Prof. K. V. Jagannadha Rao for providing the facilities. The financial assistance provided by University Grants Commission, New Delhi is gratefully acknowledged.

[11] J. Doucet and A. M. Levelut, J. Physique 38, 1163 (1977).

[12] N. V. S. Rao and V. G. K. M. Pisipati (Unpublished).

[13] B. Bahadur and S. Chandra, J. Phys. Soc. Jap. 41, 237 (1976).

[14] A. P. Kapustin and G. E. Zvereva, Sov. Phys. Cryst. 10, 603 (1966).

[15] S. Bhattacharya, B. K. Sarma, and J. B. Ketterson, Phys. Rev. Lett. 40, 1582 (1978).

[16] N. V.S. Rao and V. G.K.M.Pisipati. Phase Transitions [in press].

[17] W. L. McMillan, Phys. Rev. A4, 1238 (1971).

[18] M. R. Rao, J. Chem. Phys. 9, 682 (1941).

[19] Y. Wada, J. Phys. Soc. Jap. 4, 280 (1949).

[20] J. Frenkel, Kinetic Theory of Liquids, Dover, New York 1955.

[21] R. T. Lagemann and J. E. Corey, J. Chem. Phys. 10, 759 (1942). 